\title{
Polymorphism and circulating levels of the chemokine CXCL12 in colorectal cancer patients
}

\author{
JAN DIMBERG ${ }^{1}$, ANDERS HUGANDER ${ }^{2}$, STURE LÖFGREN $^{3}$ and DICK WÅGSÄTER ${ }^{4}$ \\ ${ }^{1}$ Department of Natural Science and Biomedicine, University College of Health Sciences, Box 1026; \\ Departments of ${ }^{2}$ Surgery, ${ }^{3}$ Clinical Microbiology, Ryhov County Hospital, SE-551 11 Jönköping; \\ ${ }^{4}$ Atherosclerosis Research Unit, King Gustav V Research Institute, Department of Medicine, \\ Karolinska Institute, SE-171 76 Stockholm, Sweden
}

Received August 16, 2006; Accepted October 2, 2006

\begin{abstract}
The chemokine CXCL12, also known as stromal cell-derived factor-1 (SDF-1), is a small protein that regulates leukocyte trafficking and is variably expressed in a number of normal and cancer tissues. CXCL12 as ligand and its receptor CXCR4 have been implicated in colorectal cancer (CRC) progression including angiogenesis and metastasis. A CXCL12 gene variant CXCL12-A (CXCL12-G801A, a single nucleotide polymorphism in the $3^{\prime}$ untranslated region) is associated with increased susceptibility to breast cancer. Based on the suggested role of CXCL12 in the pathogenesis of cancer we examined the association of the gene variant CXCL12-A with CRC. The polymorphism was analysed with PCR and RFLP methods. Furthermore, the plasma CXCL12 levels from patients with CRC were also examined. There was no significant difference in genotype distribution and allelic frequencies between CRC patients $(n=151)$ and controls $(n=141)$. On the other hand, we found that the carrying rate of allele CXCL12-A was higher in colon cancer patients compared with rectal cancer patients $(\mathrm{P}=0.017)$. Analyses by ELISA showed that CRC patients $(n=63)$ had a lower CXCL12 plasma level compared with controls $(\mathrm{P}<0.0001)$. Moreover, patients with tumours classified as Dukes' stage B and C revealed lower levels than patients with tumours in Dukes' stage A. Further studies with larger samples of patients are necessary to determine whether the CXCL12 polymorphism and plasma level reflect the clinical outcome of CRC and have an impact on CRC progression.
\end{abstract}

Correspondence to: Dr Jan Dimberg, Department of Natural Science and Biomedicine, University College of Health Sciences, Box 1026, SE-551 11 Jönköping, Sweden

E-mail: jan.dimberg@hhj.hj.se

Key words: CXCL12, polymorphism, plasma level, colorectal cancer

\section{Introduction}

Chemokines (chemotactic cytokines), a subset of small proteins $(8-11 \mathrm{kDa})$ that regulate leukocyte trafficking (1), are variably expressed in a number of normal and cancer tissues and provide the directional stimulus for the movement of macrophage and lymphocyte infiltration which effects local immunity $(2,3)$. Tumour-associated leukocytes play an important antitumourigenic role but have also been shown to contribute to the growth and spread of malignancy by inducing angiogenesis and by controlling tumour cell migration $(2,4)$.

It has been suggested that chemokines promote and regulate neoplastic progression including metastasis and angiogenesis $(5,6)$. The chemokines CCL2, CCL4, CXCL1, CXCL5 and CXCL8 have been shown to be more highly expressed in colon carcinoma compared with normal paired tissue (7), and the expression level of $\mathrm{CX}_{3} \mathrm{C}$ chemokine was found to be an essential biomarker for predicting the prognosis of patients with colorectal cancer (CRC) (8). To note, single nucleotide polymorphism in CXCL8 is associated with a reduced risk of CRC (9).

The chemokine CXCL12, also known as stromal cellderived factor-1 (SDF-1), and its unique receptor CXCR4, have been implicated in cancer metastasis of many different neoplasms where the CXCL12/CXCR4 pathway is able to activate a plethora of phenomena such as chemotaxis, proliferation and angiogenesis $(3,5,6)$. These phenomena have been shown in prostate (10), lung (11), ovarian (12), pancreatic (13), breast (14), gastric (15) and colorectal $(16,17)$ cancer.

In the gastrointestinal tract the intestinal mucosa regulates the trafficking of leukocytes into and out of the lamina propria adjacent to the epithelium. This may reflect the production of chemokines by the intestinal epithelium $(18,19)$. Both CXCR4 and CXCL12 are normally expressed in the intestinal epithelium $(17,18,20)$ but in CRC epithelium CXCR4 is overexpressed while CXCL12 seems to be partially or irregularly expressed as shown by immunohistochemical and RT-PCR analysis $(16,17)$. Fibroblasts are a common source of CXCL12, and bone marrow, the liver and lungs are organs with abundant CXCL12 expression $(5,17,21)$. These 
organs represent common sites of metastases in many cancers (5). It is likely that CRC metastases, which are found predominantly in these organs, may in part depend on CXCL12/CXCR4 interaction leading to the invasion of CXCR4-expressing CRC cells.

Furthermore, CXCL12 is a costimulator for CD4 ${ }^{+} \mathrm{T}$-cells (22), and it has been suggested that a CXCL12 gene variant, abbreviated CXCL12-A, is associated with delayed progression of AIDS, early onset of type 1 diabetes and increased susceptibility to breast cancer (23-25). This allele is a single nucleotide polymorphism in the $3^{\prime}$ untranslated region and is also designated CXCL12-3'UTR-G801A.

Based on the suggested role of CXCL12 in the pathogenesis of certain diseases we examined the association of the CXCL12 gene variant CXCL12-A with CRC. In the search for tumour markers we also intended to determine whether the plasma levels of CXCL12 in CRC patients correlated with clinical characteristics.

\section{Materials and methods}

Patients and controls for the analysis of the CXCL12 gene polymorphism. Approximately 80-90 CRC patients are diagnosed and surgically resected each year at the Department of Surgery, Ryhov County Hospital, Jönköping, Sweden. This study comprised blood samples which were obtained from 151 consecutive patients from southeastern Sweden. The patients were admitted to Ryhov County Hospital and underwent surgical resection between the years 2003-2005 for primary sporadic colorectal adenocarcinomas diagnosed at the Department of Surgery. This patient group comprised 78 males and 73 females. The mean age was 70 years (range 29-90) and all tumours were classified according to Dukes' classification system: stage A $(n=31)$, stage $B(n=60)$, stage $C(n=50)$ and stage $D(n=10)$. Seventyfive tumours were located in the rectum and 76 in the colon.

The blood-control subjects $(n=141)$ were selected $(>50$ years old) from a group of $\sim 1200$ patients from southeastern Sweden undergoing diversified blood analysis at Ryhov County Hospital. They were collected during a 2-day period. Generally about 600 blood samples arrive at this hospital daily. The controls consisted of 76 males and 65 females, and the mean age was 70 years with a range of 50-103 years. All blood samples were from individuals of Swedish caucasian origin.

Plasma samples and ELISA. Sixty-three of the CRC patients were available for plasma collection. This group comprised 34 males and 29 females, and the mean age was 68 years (range 29-89). The patient tumours were categorized according to Dukes' classification; stage A $(n=15)$, stage B $(n=26)$ and stage $C(n=22)$. Thirty-three tumours were located in the rectum and 30 in the colon. Venous blood was collected before surgery and separated by centrifugation for $1 \mathrm{~h}$. Plasma was removed and stored at $-70^{\circ} \mathrm{C}$ until assayed.

In order to determine the CXCL12 plasma level among healthy individuals, 78 controls were selected from volunteer blood donors at Ryhov County Hospital. The mean age was 60 (range, 55-67 years) years and included 41 males and 37 females. All plasma from the patients and control subjects

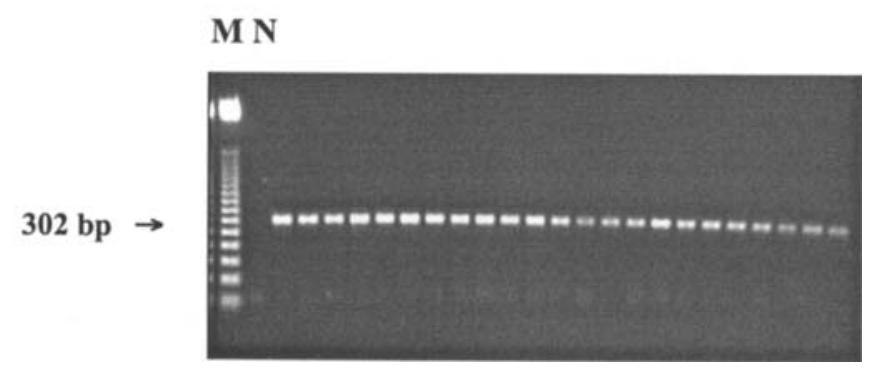

Figure 1. Agarose gel showing PCR products for CXCL12 from 23 different CRC patients. Lane M, molecular marker and lane $\mathrm{N}$, negative control.

Table I. Distribution of genotypes in \% of CXCL12 polymorphism in CRC patients and control subjects.

\begin{tabular}{lcc}
\hline Genotype & $\begin{array}{c}\text { CRC } \\
(\mathrm{n}=151)\end{array}$ & $\begin{array}{c}\text { Control subjects } \\
(\mathrm{n}=141)\end{array}$ \\
\hline $\mathrm{G} / \mathrm{G}$ & $55.6(84)$ & $57.5(81)$ \\
$\mathrm{G} / \mathrm{A}$ & $41.1(62)$ & $39.7(56)$ \\
$\mathrm{A} / \mathrm{A}$ & $3.3(5)$ & $2.8(4)$ \\
\hline
\end{tabular}

CRC patients vs control subjects, $\mathrm{P}=0.938$.

were stored at $-70^{\circ} \mathrm{C}$ until CXCL12 protein was measured using an established commercially available enzyme-linked immunosorbent (ELISA) kit (R\&D Systems Europe, UK) following the manufacturer's instructions. The plasma CXCL12 protein concentration was expressed as picograms per millilitre $(\mathrm{pg} / \mathrm{ml})$.

CXCL12 genotyping. All blood was stored frozen until DNA was extracted using a QIAamp DNA blood mini kit (Qiagen, CA, USA). The genotype of CXCL12 was identified by polymerase chain reaction (PCR). The region containing the polymorphic site CXCL12-3'UTR-G801A was amplified with primers which have been described previously (25). 5'CAGTCAACCTGGGCAAAGCC-3' and 5'-AGCTTTGG TCCTGAGAGTCC-3' were used as forward and backward primers, respectively, and were synthesized commercially (TIB Molbiol, Berlin, Germany). PCR conditions were as follows: $25 \mu \mathrm{l}$ reaction volume containing 50-100 ng genomic DNA, $0.5 \mu \mathrm{M}$ of each primer, $1.5 \mathrm{mM} \mathrm{MgCl}_{2}, 100 \mu \mathrm{M}$ of each dNTP (Promega, Madison, WI, USA), 0.6 units Taq polymerase (Amersham Pharmacia Biotech, UK) and reaction buffer $10 \mathrm{mM}$ Tris- $\mathrm{HCl}, \mathrm{pH} 8.3,25 \mathrm{mM} \mathrm{KCl}$. All of the PCR products were controlled for the presence of amplifiable DNA by electrophoresis in $2 \%$ agarose gel and visualized with ethidium bromide and UV light.

After denaturation at $95^{\circ} \mathrm{C}$ for $5 \mathrm{~min}$, the DNA was subsequently amplified for 35 cycles at $95^{\circ} \mathrm{C}$ for $30 \mathrm{sec}$, followed by annealing at $58^{\circ} \mathrm{C}$ for $30 \mathrm{sec}$, extension at $72^{\circ} \mathrm{C}$ and a final extension at $72^{\circ} \mathrm{C}$ for $10 \mathrm{~min}$. The resulting PCR product was used for restriction fragment length polymorphism (RFLP). A $10 \mu 1$ volume of the PCR reaction 
$\begin{array}{lllllllllll}1 & 2 & 3 & 4 & 5 & 6 & 7 & 8 & 9 & 10 & 11\end{array}$

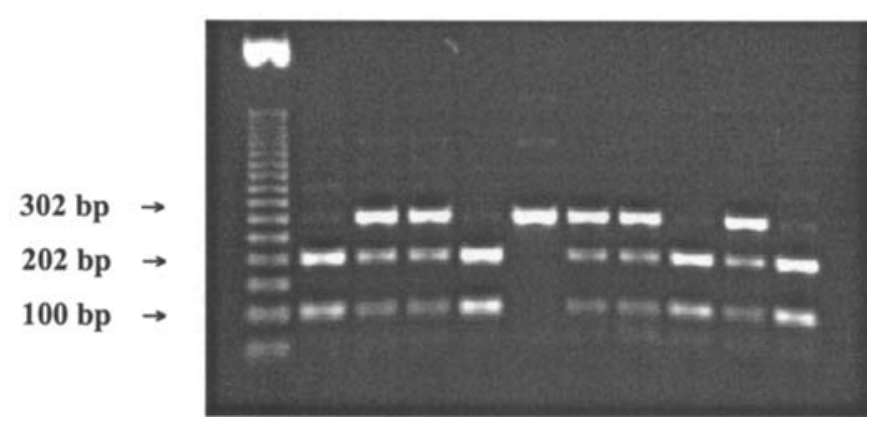

Figure 2. A representative picture from an RFLP CXCL12 genotype analysis including $10 \mathrm{CRC}$ patients. The pattern for wild-type homozygote (G/G) (lane 2, 5, 9, and 11), mutated homozygote (A/A) (lane 6) and mutated heterozygote (G/A) (lane 3, 4, 7, 8, and 10). Lane 1, molecular marker.

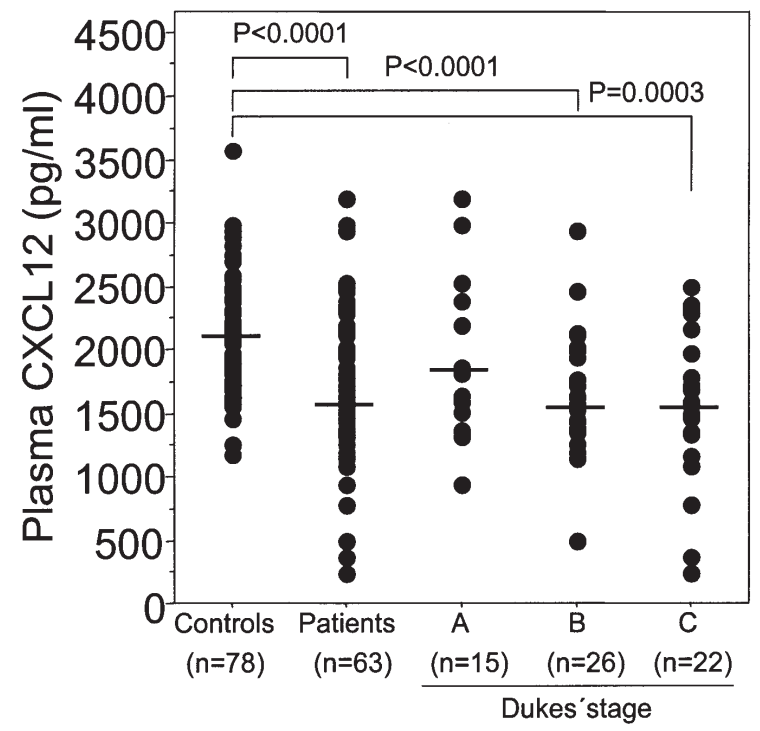

Figure 3. Plasma CXCL12 concentrations in healthy controls and CRC patients. CRC patients have significantly lower concentrations compared with controls. The difference in plasma CXCL12 concentrations between controls and patients with Dukes' stage B and C was significant. Medians are shown by horizontal bars.

product was digested with 20 units MspI (New England Biolabs, Ipswich, MA, USA) (25) at $37^{\circ} \mathrm{C}$ overnight and then analyzed by electrophoresis in $2 \%$ agarose gel stained with ethidium bromide. Undigested PCR product reflected $302 \mathrm{bp}$ representing mutated homozygote A/A. Digested PCR product is represented by a mutated heterozygote G/A (302 bp + 202 bp +100 bp) or wild-type homozygote G/G (202 bp + 100 bp).

Statistical analysis. Differences in CXCL12 plasma level between the patients and control subjects were examined by the Mann-Whitney U test. Differences in the frequencies of the CXCL12 gene polymorphism between CRC patients and the control group and between clinical data within the CRC subgroup were analyzed using the Chi-square test. Statistical analysis was performed using the SPSS for Windows
Table II. Allelic frequencies in \% of CXCL12 polymorphism in CRC patients and control subjects.

\begin{tabular}{lcc}
\hline Allele & $\begin{array}{c}\text { CRC } \\
(\mathrm{n}=302 \text { alleles })\end{array}$ & $\begin{array}{c}\text { Control subjects } \\
(\mathrm{n}=282 \text { alleles })\end{array}$ \\
\hline $\mathrm{G}$ & $76.2(230)$ & $77.3(218)$ \\
$\mathrm{A}$ & $23.8(72)$ & $22.7(64)$ \\
\hline
\end{tabular}

CRC patients vs control subjects, $\mathrm{P}=0.743$.

Table III. CXCL12 genotype and allele numbers in CRC patients.

\begin{tabular}{lcccccc}
\hline & \multicolumn{3}{c}{ Genotype } & & \multicolumn{3}{c}{ Allele } \\
\cline { 2 - 3 } \cline { 6 - 7 } & G/G & G/A & A/A & & G & A \\
\hline $\begin{array}{l}\text { Colon } \\
(n=76)\end{array}$ & 35 & 37 & 4 & & $107^{\mathrm{a}}$ & $45^{\mathrm{a}}$ \\
$\begin{array}{l}\text { Rectum } \\
(\mathrm{n}=75)\end{array}$ & 49 & 25 & 1 & & 123 & 27 \\
\hline
\end{tabular}

${ }^{\mathrm{a} C}$ Colon vs rectum, $\mathrm{P}=0.018$.

computer package (rel. 11.5, 2002, SPSS Inc., Chicago, IL). Results were considered significant at a level of $\mathrm{P}<0.05$.

\section{Results}

CXCL12 polymorphism. In order to examine the association of the CXCL12 gene variants with CRC, PCR products were cleaved and analysed. A typical agarose gel after the separation of PCR products is shown in Fig. 1, and a genotypic distribution of CXCL12 alleles after RFLP analysis is represented in Fig. 2. There was no significant difference in genotype distribution between CRC patients and control subjects (Table I) or in allelic frequencies (Table II). However, when subdividing the patients in groups, colon $(n=76)$ versus rectum $(n=75)$ (Table III), we found a significant difference regarding allele distribution $(\mathrm{P}=0.018)$. When assessing this difference we found a carrying rate of allele A to $34.7 \%$ $(26 / 75)$ in rectal cancer compared with $53.9 \%$ (41/76) in colon cancer patients. This difference was significant $(\mathrm{P}=0.017)$ with an $\mathrm{OR}=0.45$ (95\% CI, 0.22-0.92). The genotype and allelic distributions in CRC patients were not significantly different with respect to Dukes' stage, gender and age (data not shown).

Plasma levels of CXCL12. To search for tumour markers, the plasma levels of CXCL12 were measured in CRC patients and in healthy controls. The CXCL12 plasma concentrations were significantly $(\mathrm{P}<0.0001)$ lower in CRC patients $[\mathrm{n}=63$, median 1597 (range 242-3197) pg/ml] than in controls [ $\mathrm{n}=78$, median 2109 (range 1177-3572) pg/ml] (Fig. 3). With regard to the disease stage, the CRC patients were divided into 
subgroups according to Dukes' stages. Significantly lower CXCL12 plasma concentrations were noted in Dukes' stages $\mathrm{B}$ and $\mathrm{C}$ (both medians $1575 \mathrm{pg} / \mathrm{ml}, \mathrm{P}<0.0001$ and $\mathrm{P}=0.0003$, respectively) when compared with controls (Fig. 3). No difference was observed between patients in Dukes' stage A and controls. The plasma levels of CXCL12 from CRC patients were not related to age, gender, location or any CXCL12 allele/genotype investigated in this study (data not shown).

\section{Discussion}

Chemokines are chemotactic cytokines that regulate the trafficking of leukocytes. Some chemokines play an important role in lymphocyte homing and localization in the intestine. For example, the chemokine CCL25 is solely expressed in epithelial cells within the small intestine and has specificity for CCR9+ lymphocytes which affect intestinal mucosal immunity (26). The chemokine CXCL8 has been shown to be more highly expressed in colon carcinoma compared with normal paired mucosa, and a gene variant is associated with a reduced risk of CRC $(7,9)$.

In the current study we attempted to determine whether an association exists between the CXCL12 gene variant CXCL12-A and CRC. The data in this report showed that the genotype distribution and allelic frequencies were not significantly associated with CRC compared with controls. On the other hand when subdividing the patients in groups of colon and rectum cancer we found that the carrying rate of allele A was significantly higher in colon cancer compared with rectal cancer.

The influence of CXCL12 genotype CXCL12-A on CRC progression remains open as long as the functional importance of CXCL12-3'UTR-G801A in the expression of the CXCL12 transcript and protein are unknown. CRC must be seen as a disease with a polygenic background where oncogenes and tumour suppressor genes and signalling pathways participate $(27,28)$. Little is known about the crosstalk between these pathways and CXCL12/CXCR4 signalling. It has been reported that there may be a difference in the carcinogenesis of CRC based on the tumour location (29). Hypothetically a different mechanism may be involved in the pathogenesis of cancer in the colon versus the rectum depending partly on the allele CXCL12-A and thus modify the colorectal carcino-genesis. The influence of the CXCL12 gene polymorphism may contribute differentially between colon and rectal cancer in mediating tumour progression, angiogenesis, metastasis and leukocyte migration.

Circulating levels of the chemokine CXCL8 in CRC patients have previously been reported (30). The serum level of CXCL8 was noted to be significantly higher in CRC patients compared with a normal healthy group and was higher in patients with liver metastasis than in those without liver metastasis. In a search for tumour markers we find particular reason to study the levels of CXCL12 in plasma from CRC patients.

Using ELISA we noted that CXCL12 levels in healthy controls were in accordance with results from another documented healthy patient group (31). Our study also demonstrated that the levels of plasma CXCL12 in CRC patients were significantly lower than in controls, and that this difference seems to increase with a higher Dukes' stage. Extended research is required to confirm this circumstance based on additional clinical cases. It is plausible that the decreased CXCL12 plasma level in CRC patients reflects a higher degree of ligand/receptor (CXCL12/CXCR4) interactions depending on a higher expression of the CXCR4 receptor in colorectal cancerous tissue compared with normal tissue $(16,17,32)$. Moreover, earlier studies (32-34) have noted a trend showing higher CXCR4 expression with higher stages of CRC which may explain the decreased CXCL12 plasma levels in our study. However, the mechanism for the involvement of CXCL12/CXCR4 in CRC remains to be elucidated. Further studies are needed to evaluate whether the CXCL12 polymorphism affects colorectal carcinogenesis and if the plasma level of CXCL12 reflects the disease status of CRC. The results presented in this study conclude one step of a forthcoming study on tumour markers in CRC in our laboratory.

\section{Acknowledgements}

This study was supported by grants from the County Council and the University College of Health Sciences, Jönköping, Sweden. We thank Renata Kosmalska, Olof Dienus and Andrea Tompa (Ryhov County Hospital) for their excellent technical support.

\section{References}

1. Moser B, Wolf M, Walz A and Loetscher P: Chemokines: multiple levels of leukocyte migration control. Trends Immunol 25: 75-84, 2004

2. Balkwill $F$ and Mantovani A: Inflammation and cancer: back to Virchow? Lancet 357: 539-545, 2001.

3. Balkwill F: Chemokine biology in cancer. Semin Immunol 15: 49-55, 2003

4. Coussens LM and Werb Z: Inflammation and cancer. Nature 420: 860-867, 2002

5. Zlotnik A: Chemokines in neoplastic progression. Semin Cancer Biol 14: 181-185, 2004.

6. Strieter RM, Belperio JA, Phillis RJ and Keane MP: CXC chemokines in angiogenesis of cancer. Semin Cancer Biol 14: 195-200, 2004.

7. Baier PK, Eggstein S, Wolff-Vorbeck G, Baumgartner U and Hopt UT: Chemokines in human colorectal carcinoma. Anticancer Res 25: 3581-3584, 2005.

8. Ohta M, Tanaka F, Yamaguchi H, Sadanaga N, Inoue H and Mori M: The high expression of Fractalkine results in a better prognosis for colorectal cancer patients. Int J Oncol 26: 41-47, 2005

9. Landi S, Moreno V, Gioia-Patricola L, Guino E, Navarro M, de Oca J, Capella G and Canzian F: Association of common polymorphisms in inflammatory genes interleukin (IL)6, IL8, tumor necrosis factor alpha, NFKB1, and peroxisome proliferator-activated receptor gamma with colorectal cancer. Cancer Res 63: 3560-3566, 2003.

10. Chinni SR, Sivalogan S, Dong Z, Filho CT, Deng X, Bonfil RD and Cher ML: CXCL12/CXCR4 signaling activates akt-1 and MMP-9 expression in prostate cancer cells: The role of bone microenvironment-associated CXCL12. Prostate 66: 32-48, 2006.

11. Kijima T, Maulik G, Ma PC, Tibaldi EV, Turner RE, Rollins B, Sattler M, Johnson BE and Salgia R: Regulation of cellular proliferation, cytoskeletal function and signal transduction through CXCR4 and c-Kit in small cell lung cancer cells. Cancer Res 62: 6304-6311, 2002.

12. Jiang YP, Wu XH, Shi B, Wu WX and Yin GR: Expression of chemokine CXCL12 and its receptor CXCR4 in human epithelial ovarian cancer: An independent prognostic factor for tumor progression. Gynecol Oncol (Epub ahead of print, May 2, 2006). 
13. Koshiba T, Hosotani R, Miyamoto Y, Ida J, Tsuji S, Nakajima S, Kawaguchi M, Kobayashi H, Doi R, Hori T, Fujii N and Imamura M: Expression of stromal cell-derived factor 1 and CXCR4 ligand receptor system in pancreatic cancer: a possible role for tumour progression. Clin Cancer Res 6: 3530-3535, 2000.

14. Muller A, Homey B, Soto H, Ge N, Catron D, Buchanan ME, McClanahan T, Murphy E, Yuan W, Wagner SN, Barrera JL, Mohar A, Verastegui E and Zlotnik A: Involvement of chemokine receptors in breast cancer metastasis. Nature 410 : 24-25, 2001.

15. Kwak MK, Hur K, Park Do J, Lee HJ, Lee HS, Kim WH, Lee KU, Choe KJ and Yang HK: Expression of chemokine receptors in human gastric cancer. Tumour Biol 26: 65-70, 2005.

16. Zeelenberg IS, Ruuls-Van Stalle L and Roos E: The chemokine receptor CXCR4 is required for outgrowth of colon carcinoma micrometastases. Cancer Res 63: 3833-3839, 2003.

17. Brand S, Dambacher J, Beigel F, Olszak T, Diebold J, Otte JM, Göke B and Eichhorst ST: CXCR4 and CXCL12 are inversely expressed in colorectal cancer cells and modulate cancer cell migration, invasion and MMP-9 activation. Exp Cell Res 310: $117-130,2005$.

18. Dwinell MB, Johanesen PA and Smith JM: Immunobiology of epithelial chemokines in the intestinal mucosa. Surgery 133: 601-607, 2003.

19. Luster AD: Chemokines regulate lymphocyte homing to the intestinal mucosa. Gastroenterology 120: 291-294, 2001.

20. Agace WW, Amara A, Roberts AI, Pablos JL, Thelen S, Uguccioni M, Li XY, Marsal J, Arenzana-Seisdedos F, Delaunay T, Ebert Ec, Moser B and Parker CM: Constitutive expression of stromal derived factor-1 by mucosal epithelia and its role in HIV transmission and propagation. Curr Biol 10: 325-328, 2000.

21. Luker KE and Luker GD: Functions of CXCL12 and CXCR4 in breast cancer. Cancer Lett 238: 30-41, 2006.

22. Nanki T and Lipsky PE: Cutting edge: stromal-derived factor-1 is a costimulator for CD4+ T-cell activation. J Immunol 164: 5010-5014, 2000.

23. Winkler C, Modi W, Smith MW, Nelson GW, Wu X, Carrington M, Dean M, Honjo T, Tashiro K, Yabe D, Buchbinder S, Vittinghoff E, Goedert JJ, O'Brien TR, Jacobson LP, Detels R, Donfield S, Willoughby A, Gomperts E, Vlahov D, Phair J, ALIVE Study, Hemophilia Growth and Development Study (HGDS), Multicenter AIDS Cohort Study (MACS), Multicenter Hemophilia Cohort Study (MHCS), San Francisco City Cohort (SFCC) and O'Brien SJ: Genetic restriction of AIDS pathogenesis by an SDF-1 chemokine gene variant. Science 279: 389-393, 1998.

24. Dubois-Laforgue D, Hendel H, Caillat-Zucman S, Zagury JF, Winkler C, Boitard C and Timsit J: A common stromal cellderived factor- 1 chemokine gene variant is associated with the early onset of type 1 diabetes. Diabetes 50: 1211-1213, 2001.
25. Zafiropoulus A, Crikas N, Passam AM and Spandidos DA: Significant involvement of CCR2-64I and CXCL12-3a in the development of sporadic breast cancer. J Med Genet 41: e59, 2004.

26. Kunkel EJ, Cambell JJ, Haraldsen G, Pan J, Boisvert J, Roberts AI, Ebert EC, Vierra MA, Goodman SC, Genovese MC, Wardlaw AJ, Greenberg HB, Parker CM, Butcher EC, Andrew DP and Agace WW: Lymphocyte CCR9 and epithelial TECK expression distinguish the small intestinal immune compartment: epithelial expression of tissue-specific chemokines as an organizing principle in regional immunity. J Exp Med 192: 761-768, 2000.

27. Fearon ER and Vogelstein B: A genetic model for colorectal tumorigenesis. Cell 61: 759-767, 1990.

28. Smith G, Carey FA, Beattie J, Wilkie MJ, Lightfoot TJ, Coxhead J, Garner RC, Steele RJ and Wolf CR: Mutations in APC, Kirsten-ras, and p53-alternative genetic pathways to colorectal cancer. Proc Natl Acad Sci USA 99: 9433-9438, 2002.

29. Konishi K, Fujii N, Boku S, Kato I, Ohtsu A, Tajiri H, Ochiai A and Yoshida S: Clinicopathological differences between colonic and rectal carcinomas: are they based on the same mechanism of carcinogenesis? Gut 45: 818-821, 1999.

30. Ueda T, Shimada E and Urakawa T: Serum levels of cytokines in patients with colorectal cancer: Possible involvement of IL-6 and IL-8 in hematogenous metastasis: J Gastroenterol 29: 423-439, 1994.

31. Zannettino ACW, Farrugia AN, Kortesidis A, Manavis J, To B, Martin SK, Diamond P, Tamamura H, Lapidot T, Fujii N and Gronthos S: Elevated serum levels of stromal-derived factor- $1 \alpha$ are associated with increased osteoclast activity and osteolytic bone disease in multiple myeloma patients. Cancer Res 65: 1700-1709, 2005.

32. Ottaiano A, di Palma A, Napolitano M, Pisano C, Pignata S, Tatangelo F, Botti G, Acquaviva AM, Castello G, Ascierto PA, Iaffaioli RV and Scala S: Inhibitory effects of anti-CXCR4 antibodies on human colon cancer cells. Cancer Immunol Immunother 54: 781-791, 2005.

33. Kim J, Takeuchi H, Lam ST, Turner RR, Wang HJ, Kuo C, Foshag L, Bilchik AJ and Hoon DS: Chemokine receptor CXCR4 expression in colorectal cancer patients increases the risk for recurrence and for poor survival. J Clin Oncol 23: 2744-2753, 2005.

34. Ottaiano A, Franco R, Aiello Talamanca A, Liguori G, Tatangelo F, Delrio P, Nasti G, Barletta E, Facchini G, Daniele B, Leonardi E, Albino V, De Angelis V, Falanga M, Boccia V, Capuozzo M, Parisi V, Botti G, Castello G, Vincenzo Iaffaioli R and Scala S: Overexpression of both CXC chemokine receptor 4 and vascular endothelial growth factor proteins predicts early distant relapse in stage II-III colorectal cancer patients. Clin Cancer Res 12: 2795-2803, 2006. 